\title{
An Innovation in Informal Adult Education: Mother to Mother Learning in the Australian Breastfeeding Association
}

\author{
Margaret Mary Carmody \\ Australian Catholic University, Research Services Melbourne Campus
}

\begin{abstract}
To understand the Australian Breastfeeding Association's approach to adult education and the educational practices it introduced into maternal education in Australia in the period 1964-2009, it is useful to consider adult education generally and maternal education specifically during the twentieth century. Most of what passes for education of mothers is informal adult education. One view is that mothers require expert instruction and supervision with regulation of feeding to ensure their babies survive. The opposite view is that mothers should receive no formal instruction at all about being mothers: breastfeeding and caring for babies are, in this view, instinctive activities. However, the Association's approach has featured autonomous learners with volunteer facilitators in informal settings. One theory that assists particularly in understanding the educational model used by the Association is the humanistic theory of adult education. Another theory relevant to maternal education is a heutagogical approach to adult education, advocated by radical adult education theorists. To understand the Association's educational approach, it is necessary to establish the core principles of the education provided to mothers by the Association. The archival research has demonstrated an understanding of the Association's approach to maternal education. The primary feature of the approach is mother to mother learning. The findings of this paper will increase knowledge of how adults are educated and contribute to understanding of adult education, particularly maternal education. There will be implications for education of mothers and perhaps of women generally which will be of interest to those involved in adult education.
\end{abstract}

\section{Introduction}

Imagine a world where no one can tell mothers how to feed naturally, where it seems as though almost everyone has forgotten what a normal, natural breastfeeding relationship between mother and baby is, and forgotten the importance of breastfeeding to the mother, the baby and society as a whole. This was the world that faced a young mother, Mary Paton, living in Melbourne in the 1960s, where, like the rest of Australia, there had been a steady decline in breastfeeding rates since World War II. In response to this situation, Mary Paton, along with a few of her friends, began a voluntary association to support mothers who chose to breastfeed their babies and provide them with reliable information about breastfeeding, in the face of overwhelming medical and community support for artificial feeding. This voluntary association, the Australian Breastfeeding Association (ABA), which Mary Paton began in 1964 as the Nursing Mothers' Association (NMA) and became the Nursing Mothers' Association of Australia (NMAA) is today one of the largest voluntary women's associations in Australia [1].

This paper argues that there was a successful challenge to perceptions of motherhood by the Association in its first 45 years, from 1964 to 2009, with particular emphasis on its innovative mother to mother education in the area of breastfeeding and its contribution not only to the changing knowledge about motherhood but also to the discourse of infant nutrition. It also argues that the Association played a major role in the improvement in breastfeeding rates in Australia 1964 - 2009: that Mary Paton devised a new method of educating mothers about infant nutrition and breastfeeding.

\section{Aims}

The aims of this paper are to consider the contribution, over its first 45 years, of the Association as an adult education provider. It addresses specifically the Association's approach to adult education and the educational practices it introduced into maternal education in Australia. The first section is a literature review of adult education, particularly informal adult education and identifies the major theoretical approaches. This section also provides an analysis of the educational approaches taken in the maternal education provided to mothers in Australia in the first half of the twentieth century. It will explore the educational methodology employed in a variety of forms of education provided to mothers by many different organisations in a variety of settings. The second section of this paper will examine the role of Mary Paton and the founders in setting up the Association in 1964, the role of the Association in changing maternal education in Australia and its effects on breastfeeding in Australia. 


\section{The breastfeeding landscape}

It is very difficult to know how many babies have been breastfed at any time in the twentieth century in Australia. There have been no consistent surveys and there has been no serious attempt to find out until recently. Moreover, the statistics that are available are confusing because the surveys do not use consistent definitions, and do not ask the same questions, despite the World Health Organisation definitions for full, exclusive and partial breastfeeding. There are important implications for researchers from this inconsistency which have resulted in contradictory conclusions. [2]

For the period up to the mid-1980s, when the Australian Bureau of Statistics conducted a National Health Survey, it is necessary to rely on state based surveys which are not really comparable because they have used varying definitions of breastfeeding and their questions have not been consistent. In Australia, there has been promotion of breastfeeding nationally and in state policies as the desirable feeding practice, however, this promotion and writing of policies has not resulted in consistent definitions of important aspects and levels of breastfeeding. This makes it very difficult for researchers to know what has happened and it makes it difficult for policy makers interpreting data.

It appears that the most comprehensive statistics are those available for the Australian state of Victoria which is the second most populous state with the highest education levels and a comparatively low Indigenous population. In Victoria, the decline in breastfeeding in the postWorld War II period was from almost half of babies' breastfed at three months in 1950 to less than a third by 1961 and indeed continued to decline to one fifth by 1971 . For babies aged six months, the decline was from less than two fifths in 1950 to one fifth in 1961 and down to less than one in ten by 1971. "These data from Victoria are likely to be indicative of long term time trends for breastfeeding rates for Australia at the national level." [3] What is apparent from the various surveys, however, is that, apart from surveys such as the one of Rural Aboriginal Groups in Western Australia in 1983 where 99\% of babies were breastfed at three and six months they all indicate levels of breastfeeding which are far lower, particularly at age six months, than the national goals and targets which have not met in the past and still do not currently meet the World Health Organisation guidelines.

The reaction to concerns about low breastfeeding rates has been attempts to educate mothers and in so doing to regulate and control the situation. To understand the methods of education employed, it is useful to consider adult education generally and maternal education specifically.
There is very little literature that discusses specifically the theory of maternal education. To seek an understanding of the educational approaches that have been employed it is necessary to review the work of theorists about adult education in general and then examine the writings of the health professionals who provided the education to look for clues as to their methodology and their theoretical base. There are also histories of women's organisations to consider, indeed, much research into the history of the Association has already been completed: this paper views these resources from an adult education perspective.

\section{Informal adult education}

Most of what passes for education of mothers is informal adult education. It is not offered as a certificated course at a technical college or a degree at a university, however, informal maternal education is ubiquitous in our community. ${ }^{[4]}$ Livingstone defines informal education as "when mentors instruct novices in spontaneous learning situations without sustained reference to an intentionally organised body of knowledge". ${ }^{[5]}$ On any given day, across Australia, mothers have been engaged in informal education in a variety of settings such as local baby health clinics, maternity hospitals, community centres and private homes. While lifelong learning is supported and encouraged by the UNESCO Institute for Lifelong Learning, informal adult learning receives less attention than other areas. This is of concern because informal adult education encourages social participation. Precisely because it is informal education and it is ubiquitous in the community, it is often ignored and moreover, the ways that adults learn generally are often misunderstood.

It has been suggested that there are three main ways that adults learn: natural learning, which is learning that occurs in the individual's environment in their usual social interactions with friends and family and is essentially informal learning; formal learning, which occurs in institutional settings such as school where the format and material is selected by others and lastly, personal learning which involves self-directed, purposeful learning activities such as private reading on a topic of interest and may be formal learning if it is part of a course or informal learning if it is not part of a structured course. This delineation of three kinds of learning is particularly useful in understanding what has occurred in educating mothers, especially about infant nutrition.

There are various views on the matter of how to educate mothers. The first view is that mothers require instruction and training followed by supervision in order to be competent mothers and to ensure the survival of their babies. [6] The opposite view is that mothers should receive no formal 
instruction at all about being mothers: breastfeeding and caring for babies are, in this view, instinctive activities, which mothers can learn by following their own instincts and by observation of other mothers. [7] Between these two extremes, there exist all colours of different approaches, which are important when considering the transformative role of education of mothers [8]. It could be argued that women learnt traditionally, about mothering and breastfeeding, not through instinctive learning, but rather through natural learning; that is, they picked it up as they went through their lives, by observation of mothers breastfeeding in their social circle and by practicing the skills of looking after babies, when caring for younger siblings and playing with neighbours' and friends' babies.

However, this traditional approach came to an abrupt end, when, in alarmed response to concerns about infant mortality, poverty and poor housing in the late nineteenth and early twentieth centuries, governments and various health professionals in Australia and elsewhere began formal education of mothers, using set curriculum, handbooks and formal classes in institutional settings with "time governed tasks" [9]. This formal learning was effective in reducing infant mortality, but at the same time, caused the discrediting of natural, informal learning and the transformation of thinking about motherhood and infant nutrition. In addition to the formal learning, personal informal learning took place in the form of mothers reading magazines and newspaper advice columns, as well as handbooks written by experts [10].

\section{Theories of adult education}

None of the theorists of adult education has described or analysed specifically maternal education, however, their theories are relevant to this paper as a means of analysing the various forms of maternal education offered to mothers.

Theories of adult education have been constantly reviewed and revised throughout the late nineteenth and twentieth centuries. In considering the approach of the Association, it is pertinent to consider these theories, their origins, and the resulting views of adult education.

The teacher centred pedagogical approach championed by Skinner has realist and scientific underpinnings: its appropriateness for teaching adults has been questioned by humanistic writers such as Maslow and Knowles [11]. There are variations to this approach, where students learn from each other as well as from the teacher such as in the approach used by the arts and crafts movement of adult education, which was based on liberal theories of education and is often employed in adult education such as occupational therapy [12] This may have influenced the founders of the Association as some of them were themselves Occupational Therapists.

One theory that assists us particularly in understanding the model of education used in informal adult education is the humanistic theory of adult education. The humanistic, learner centred approach has its origins in Maslow's thinking and had an influence on adult education in the 1950s and 1960s. Learner centred education essentially provides "safe, supportive and collaborative environments where adult learners construct their own knowledge" and they do not feel oppressed [13] Knowles' writing was the first serious consideration that educating adults was fundamentally different from educating children and with this came a specific use of the term andragogy to conceptualise adult education: it has been described as the "Leading 'brand' in adult education theory". Andragogy has the meaning of the science of understanding and supporting lifelong and "life wide" education of adults. Knowles' concept of the adult learner was based on the humanistic concept of the adult learner as self-directed and autonomous and the teacher as a "facilitator" of learning. The elements are preparation; setting; planning; diagnosis of learning needs and objectives; design and delivery of learning plans; and evaluation of personal learning outcomes. Andragogy, according to Knowles, positions the teacher not as the authoritative Taylorist leader, but rather as the learning facilitator, enabling the adult students to learn. Essentially, Knowles' model of adult education involves informality and for this reason, it is relevant to much of maternal education. The difficulty in assessing maternal education is that, as Fowler says, "The knowledge gained through informal and incidental learning may not always be accepted or identified as knowledge as it is difficult or may be impossible to construct this knowledge discursively within available language or replicate women's experiences as mothers" [14].

In a radical challenge to behaviourism, there emerged the progressive theory of adult education, championed by Dewey and Lindeman who advocated that the function of adult education is to assist the students to participate in society, to teach them to solve problems and to learn by investigating cooperatively from experience and to reflect on that experience [15].

Two other theories of adult education are relevant to a discussion of maternal education. Selfdetermined learning, that is, a heutagogical approach to education of adults, is advocated by radical adult education theorists. Radical adult education has a strong commitment to social justice and the empowerment of oppressed minorities. In addition, some scholars have asked whether women learn differently from men and whether there needs to be a model of women's learning called “gynaegogy. [16]. 
If this is the case, then it could be argued that the method of adult education devised for maternal education needs to be viewed in this particular light and whether it constitutes "gynaegogy", concentrating as it does almost exclusively on the learning of adult women. This is of special concern when analysing maternal education provided to mothers who are invisible such as women prisoners and young mothers still at school.

\section{Influences on mothers}

The major influences on Australian mothers during the twentieth century as they learnt to be mothers were complex and included; the media, especially women's magazines which depicted artificial feeding as modern, the health professionals including doctors and nurses who strongly advocated breastfeeding but in such a rigid format that it was bound to be unsuccessful and the hospitals themselves which wanted the most efficient method for their own convenience. The instruction from both formal and informal sources potentially caused problems for the young mother with her own mother.

Influential on mothers and health professionals in the nineteenth and early twentieth centuries in the United Kingdom, in France and in Australia and New Zealand were works such as Bull's handbook, The maternal management of children, in health and disease, Budin's The Nursling, Sykes' Mothercraft and handbooks such as Langton Hewer's Our baby: for mothers and nurses and Truby King's Feeding and caring for baby. Then, later in the twentieth century, Benjamin Spock in the United States wrote the "Bible" of childcare, Mary White, also in the USA, founded the La Leche League and Mary Paton founded the Association in Australia.

Traditionally, medical courses paid very little attention to breastfeeding which fell into "the complex and often conflicted space between formal professional knowledge about health and personal and experiential and embodied knowing's and learnings" [17]. This gap provided the space which Truby King and other experts were keen to fill.

Sykes and Truby King convinced mothers in the first half of the twentieth century to adopt practices with regard to mothercraft, particularly infant nutrition, which were radically different from the practices of mothers before that time. These practices were based on scientific thinking, and particularly on behaviourist psychology. Their appeal lay in the conspicuous success of modern scientific methods on problems such as rickets, whooping cough and other diseases. When a scientific approach was applied to the matter of mothering and in particular, infant nutrition, it sought to control the activities of mothers to render them efficient and consistent. Such efforts were directed to regulation and education especially of low income families based on an assumption of their deficiencies in parenting skills. This was accompanied by increasing professionalisation with the registration of midwives and specialist training for maternal and child health nurses. Although they claimed to support breastfeeding, the rigid routines, attention to cleanliness and hygiene and minimal handling of the infant, which they advocated, made breastfeeding almost certain to fail. These experts discouraged bonding between mother and baby and were obsessed with feeding by the clock, and measuring progress by certain criteria, mainly regularly weighing and measuring baby. This was the minimalist mothering approach, which simplified baby care into a set of rules to be followed and was enforced strictly by nursing sisters in baby health clinics and reinforced via the media. Increasingly as the new methods became widely accepted, formula feeding was depicted as modern, progressive and desirable because it gave mothers the freedom to do things other than feed their babies.

The minimalist mothering approach regarded mothers as "unreliable" and depended on authoritarian clinic sisters and doctors to supervise them and on the efforts of energetic philanthropic volunteers supported by governments to administer vast systems of care in Australia, as in the United Kingdom and New Zealand. Many of these organisations such as the Red Cross Society and the Country Women's Association and the various mother craft societies were begun by volunteers in Australia, but over time the responsibility shifted slowly to governments, at all levels from local to Federal.

Local Governments and health departments all over Australia concerned about infant mortality and morbidity in the early 1900s had established or supported baby health clinics in cities and large towns. They were an extension of public health and became part of far reaching systems of maternal and child health throughout Australia. In Australia, there were influential health professionals such as Roberta Jull in Western Australia, Margaret Harper in New South Wales, Helen Mayo in South Australia, John Springthorpe and Maude Primrose in Victoria and politicians such as Joseph Lyons, Edith Cowan and Innes-Noad along with bureaucrats who strongly influenced provision of maternal and child health. This scientific approach to the matter of infant mortality with rigid regulation, instruction and supervision was undoubtedly successful, such that, in 1937, South Australia had the lowest infant mortality in the world. Similar claims had been made by Truby King earlier in Dunedin, New Zealand [18]. But this decline in infant mortality came at a price because there was a corresponding decline in breastfeeding which was not the intention of experts such as Truby King, but was the inevitable result of restrictive regimes of regulated feeding by the clock and minimal handling of infants. 
Over time, these rigid systems were themselves seen as dated and were replaced in the post-World War II period by the much less authoritarian ideas about mothercraft and childcare of the American paediatrician Dr. Benjamin Spock who encouraged mothers to consider what suited them and their baby best as they made decisions about infant nutrition [19].

However, Spock's views were fundamentally premised on the same ideas of routine and regularity and, assuming the equivalence of breast and bottle feeding, advocated the latter as the modern way. Bowlby's research into maternal deprivation and detailing of the importance for a child of a "warm, intimate and continuous relationship with his [sic] mother" greatly contributed to changing views about infant nutrition and caring for babies in the postWorld War II period as did the changing media depiction of women and of mothers in particular [20].

In addition, department stores influenced women's views of themselves and their bodies and promoted fashionable foundation garments. In 1956 in the USA, Mary White founded the La Leche League to support mothers who wanted to breastfeed and in 1963 published The womanly art of breastfeeding. In Australia, Parent Centres Australia and the Childbirth Education Association began, both of which had the specific intention of providing parents with information about pregnancy, childbirth and parenting, taking a confrontational approach to the medical fraternity. And then in 1964, Mary Paton founded the Association, providing mothers with information about breastfeeding but taking a nonconfrontational approach to the medical authorities.

These changes in women's lives and the way they cared for their babies are documented in histories of Australia, which discuss women and their organisations. There are numerous histories of the various providers, both individuals and organisations, of maternal welfare and maternity services. These include Reiger's biography of Maud Primrose or Crisp and Ruddock's account of the Canberra Mothercraft Society, The Mothering Years and there are celebrations of the Plunket Society such as Bryder's $A$ voice for mothers: The Plunket Society and infant welfare 1907-2000. There have been a number of histories written about the infant welfare movement in Australia and, while it is not their primary focus, each of these histories makes useful observations about maternal education. These histories have sections devoted to baby clinics and they tell the tale of increased medicalisation of baby rearing and housekeeping, the spread of the baby clinics and the decline in infant mortality. In the work of Kociumbas, Bryder, Mein-Smith and Reiger, women's organisations are depicted as playing an important role in supporting mothers in their daily lives.
There were many nineteenth century doctors in Australia who published advice on topics related to women's and children's health. Kociumbas argues that these publications had a far greater effect than merely providing information about infant nutrition. "In these publications, colonial doctors offered a complex formula designed to transform the ideal of home as a blessed sanctuary into a quasi-military factory for manufacturing a 'national type' suitable for industry and global war" [22]. This is a theme of Kociumbas' book and it indicates her concern that the expert was taking over the domestic scene and the power and knowledge of the mother was being consciously undermined. The increasing scientific control of the household had many benefits with regard to controlling illness, however, it "demanded their mothers' unprecedented personal vigilance and domestic hygiene". With new discoveries about the components of food such as vitamins, doctors became involved in advising mothers what to feed children, including when and how to breastfeed them. Kociumbas uses as an example a publication distributed by the NSW Department of Public Instruction in 1914 showing how to feed a baby by the clock. There was a feeling of loss of status for the mother as the experts took over and described demand feeding, rather than feeding four hourly, or by the clock, as "pernicious". In attempts to improve infant and maternal health medical and government powers and various organisations attempted to control the lives of women who were poor and marginalised by virtually punishing them. Kociumbas identifies the various organisations, which sought to enhance and control childhood in Australia including philanthropists, various religious orders of nuns and medical experts.

The influence of Truby King and his Plunket system was felt very strongly in Australia as the nurses working in infant welfare in Australia had typically trained as Plunket nurses in New Zealand where, by the mid-1930s, Truby King's Plunket system was well established, such that $65 \%$ of all non-Maori infants were under the care of a Plunket nurse. Curiously, Maori mothers and their babies in rural New Zealand were not involved. The First World War fuelled the celebration of babies with the first New South Wales Baby Week in 1920 using the slogan "Long Live King Baby". In Australia and New Zealand, the Plunket Baby "came to stand for the better British type" [22].

The infant welfare movement in Australia has rapidly evolved. According to Mein Smith, maternal education had little influence: general education of children had a far greater influence on the practices that mothers adopted and thus, choosing to not breastfeed is seen as evidence of "women's increasing self-realization". Reiger has written a number of histories about the lives of Australian women in the twentieth century, including the 
disenchantment of the home and our bodies, our babies: the forgotten women's movement. The organisations which have supported women in their traditional role of mothering have been very important in the lives of Australian women; Reiger positions them as ignored by academic feminism and producing a different type of political activism where change came overwhelmingly from mothers in the community, rather than from the medical authorities or from government. There was a very strong growth in the organisations that supported mothers in the 1960s and 1970s, including the Childbirth Education Association, the Homebirth Association and the Association, however, the Association, concentrating as it did on breastfeeding, rather than pregnancy and birth did not cause the same antagonism with the medical establishment. The historians point to the white middle class origins and the lack of participation of Indigenous women in these organisations with the implications for the children's health.

There were dilemmas facing women and the provision of maternal health, and part of this dilemma was that the provision of maternity services and infant welfare was limited to a particular view of women's role in Australian and New Zealand society as the providers of strong healthy children to build up the Empire. All of the books about individuals and organisations give us insight into influences on the lives of women as they cared for their babies. However, none of these histories places the work of the various organisations and the individuals within the broad context of adult education and in particular, maternal education

\section{Emerging themes}

There are themes emerging from the research: why women joined the Association, their experience of breastfeeding, the resources they found helpful in learning about breastfeeding and the aspects of the Association's approach that assisted them in their mothering role.

The primary feature of the Association's approach to maternal education is mother to mother learning. This feature distinguishes the Association's approach from that of all preceding organisations. Rather than relying on medical and nursing professionals to instruct and supervise mothers, the Association relied and still does rely on mothers learning from each other. The trained voluntary Counsellors are all mothers themselves with extensive personal breastfeeding experience and this fact alone seems to provide them with a practical understanding of the feelings and thoughts and experiences of the mothers who come to the Association for assistance with and information about breastfeeding. Mothers have found that the resources of the Association particularly the booklets on breastfeeding topics, which were written by mothers themselves, were especially useful, primarily because they typically provided mothers with a range of options for how to proceed, to fit a variety of personal circumstances. This is a far cry from the rigidity of earlier maternal education such as Truby King's which with its famous clock face, laid down rules regarding timing and frequency of feeds, insisted on four hourly feeds and discouraged contact with the baby. It is apparent from the research that mothers found the Association's approach useful as they cared for their babies, and young children.

Another of the features of the Association's approach that is evident in their published resources from the period is the use of language. The language itself is quite unlike earlier manuals and handbooks for mothers. The Association's resources are written by mothers and they use the same language that mothers use when talking to each other, rather than using scientific or medical language which is intended to give the author authority, but at the same time risks disempowering the mother into an obedient follower of instructions, dependent on the expert. This was an approach, utilizing mothers' own knowledge, their language and their friendship to impart knowledge and to encourage mothers to make up their own minds, which constituted a new theory of maternal education, unique to the Association.

Sources of data of this research include theorists of adult education, some semi structured interviews conducted in Australia and New Zealand, the existing oral histories lodged in the Queensland State Library, the writings of key providers of maternal education and sources such as newspapers, magazines and films about infant nutrition, which influenced mothers in their thinking and behaviour. The area of breastfeeding in Australia is typified by historical paucity, that is, there is very little factual evidence in documents or in statistical surveys. It is appropriate, in seeking to understand what mothers did and how they learnt about breastfeeding to augment what little information exists with oral history. The oral histories together with the interviews provide a wealth of material for the researcher. They are an opportunity for women to tell their stories and they are a rich and varied source of information for this research, providing as they do, links between the published facts and people's experiences, their practices and opinions of the past and their possibly changing views over time. In the oral histories, the mother is central, the experts are peripheral. This relationship is pertinent to a consideration of ways of talking about breastfeeding and infant nutrition because they may have been affected by the terms used by the dominant historical discourses of childbirth, maternal health and infant care. 
Often, the material regarding the area of maternal education depicts the mothers and their babies as objects to be instructed rather than participants in the process of education. This is especially so when reading midwifery and medical texts and handbooks, both those written for the health professionals and those written for mothers. In the area of maternal education, it has been the health professionals who have been the great and powerful, joined by philanthropists, bureaucrats and business. The significant fact is that they do not give us the individual voices of the women in the way that oral histories can.

With oral history, it is possible to discern beliefs and practices about breastfeeding from listening to the stories that the participants tell. Cultural practices emerge and embedded messages about breastfeeding are identifiable. In further research, this material will be augmented by more semi structured interviews with participants, both mothers and education providers.

To that end, a detailed model of the education method of the Association will be constructed from the information and data collected. The use of language in relation to maternal education and breastfeeding will be examined in depth, with regard to power relations between the providers of the education and the learners, the mothers. Studies of adult education, particularly women's education will be analysed to give insight into approaches to maternal education.

From the interviews, and the oral histories already collected, patterns of behaviour and attitudes to mothers, to babies and to breastfeeding are emerging. Participants often mention the typical features of their experience of participating in Association activities and their experience of learning about breastfeeding through the Association's Counsellors, the discussion groups and the Association's printed resources. The first aspect that many of them dwell upon is their initial contact with the Association. Often this was via the media, such as a magazine or newspaper article they read. This may indeed have been several years before they had a baby of their own, but it obviously made an impression, so that when the time came and they had a baby, they sought out the Association for information and for companionship in their new role of being a mother. Other mothers reported that they were urged to make contact by family members who had successfully breastfed their own babies and had found the support of the Association to be valuable. One interviewee said she initially went to a discussion because her husband had urged her to go to get value for the money she had paid to be a Member. Others said they initially made contact because they wanted to purchase an item that the Association sold such as a lambskin. In these cases, it was the friendly helpful response from the Member of the local Group who held the role of Sales that encouraged them to become involved in the Association.

Regardless of the reason for initial positive feelings about the Association or the events that led mothers to make contact, the interviewees then remarked in detail about their experience of attending Association discussions, especially the first one they attended. This strong memory of that first discussion suggests that it must have been a very memorable event. It suggests that it was in many ways quite different from any other forms of maternal education that these mothers had attended. The discussions they described had an air of informality about them, yet a lot of information was learned. They were led by a trained Counsellor with question and answer format and flexibility to focus on the needs and concerns of those present. The interviewees also mention the individual contributions to problem solving and that these were valued by the Counsellor and by the other mothers who attended.

Overwhelmingly the oral history resources examined describe an empathetic group where there is non-judgmental understanding of the complexity of the problem such as unsettled baby, low weight gain and so on. In a world of conflicting advice from clinic sisters, doctors and family members, not to mention the media, this sense of understanding is a first step for a mother to make up her own mind how to proceed, to become an autonomous learner. This sense of understanding what it is like for the mother as she copes with a baby is something that the interviewees also found in the printed resources of the Association, the Newsletter, the booklets and the books.

The role of the Counsellors both in leading discussion groups and in other interactions with mothers, including telephone and face to face counseling, appears to have been quite different from the role of the Plunket Nurses, the midwives in the hospitals and other health professionals. There is a noticeable tendency to talk about Counsellors as helping rather than teaching: the participants have used language such as "She helped me a lot" or "I learnt ...'. This indicates a role of a facilitator of learning rather than an instructor or a teacher or indeed a supervisor of "unreliable" mothers.

In the oral histories, participants often mention large groups of $30+$ mothers and their children at Association discussions and morning teas. They describe the chaotic environment of many mothers and their babies and toddlers gathered together in a Member's home or a local community hall. They also remarked on their initial surprise at the willingness on the part of mothers to breastfeed in that "public place". This was a novel experience for many new mothers. The interesting aspect of this is that this setting for learning is totally different from 
the setting that health professionals used in the ante natal classes and the clinics and indicates an awareness of the fundamental adult learning principle of appropriate setting for learning as set out by Knowles.

With further interviews, it will be possible to categorize the information based on their views of and involvement in the Association, their interest in breastfeeding, how and where they learnt about breastfeeding, their opinion of the Association's approach to teaching mothers about breastfeeding, and the resources they found useful. In addition, there will be categories to do with their experience of the Association's Counsellors, its Code of Ethics, its mother to mother education, its Community Education and finally any other general comments.

It was a courageous little band of women, led by Mary Paton, who dared to seek information about breastfeeding in order to support mothers who wanted to breastfeed their babies. They did not do this by setting up an institution or a system of expert professionals to instruct mothers but rather established informal groups run by volunteers, planning their own topics, learning in domestic or local community settings where the focus was on the learner rather than the teacher or the curriculum and where mothers primarily learnt from each other: mother to mother learning.

\section{Conclusion}

This paper has reviewed the different approaches to educating mothers, identifying the two extremes of a scientific approach versus instinctual and arguing that the Association does not fit neatly into either approach, but rather does something quite different. It has described the benefits to the education of mothers of a liberal approach such as that used by the arts and crafts movement here in Australia.

It has reviewed the writing of various historians of the twentieth century in Australia and New Zealand who have examined the major organisations which provided maternal education such as the Plunket Society in New Zealand and the Association in Australia. However, it is apparent that their examination has depicted the role of women in society generally and the organisations which influenced and supported them, but none of these histories has examined the Association as a provider of informal adult education. Thus, this paper has identified a gap in the research about how best to educate mothers in their mothering role and how to breastfeed successfully and specifically, a gap in the research as to how the Association educated mothers. This is unsurprising as, informal learning typically is neither documented nor analysed. This is an important area to address in Australia's provision of adult education and the resulting development of Australia's social capital.

This paper has broadened the analysis of the activities of the Association and its members to include maternal education as a distinct part of the broad movement of informal adult education. To understand the approach of the Association, it is necessary to establish the core principles of the education provided to mothers by the Association. The findings of this paper will increase knowledge of how adults are educated and contribute to understanding of adult education, particularly maternal education. There will be implications for education of mothers and perhaps of women generally which will be of interest to those involved in adult education. This is the gap in the research about maternal education that needs to be addressed.

This paper is limited to a consideration of the Association as a provider of education to mothers in the period $1964-2009$. It has argued that the key to the Association's success was that Mary Paton, together with the Founders, devised a new method of educating mothers about infant nutrition and particularly breastfeeding: they established simultaneously a community of learners and a community of practice.

\section{References}

[1] Australian Breastfeeding Association. (2011). Australian Breastfeeding Association [Online]. Melbourne. http://www.breastfeeding.asn.au/default.htm. Australian Health Ministers' Conference 2009. Australian National Breastfeeding Strategy. Canberra, ACT: Australian Government Department of Health and Ageing.

[2] Mcintyre, E., (1998). Defining breastfeeding. Australian and New Zealand Journal of Public Health, 22, 627-627.

[3] Australian Institute Of Health And Welfare and Lester, I. H., (1994). Australia's Food and Nutrition. Canberra, ACT: Commonwealth of Australia. pp. 304, 191, 308

[4] Knowles, M. S., Holton, E. F. and Swanson, R. A., (2005). The adult learner, Burlington, MA: Elsevier.

[5] Livingstone, D. W., (2007). Re-exploring the icebergs of adult learning: comparative findings of the 1998 and 2004 Canadian surveys of formal and informal learning practices. The Canadian Journal for the Study of Adult Education, 20, 24.

[6] Sykes, J. F. J., (1910). Mothercraft. The Journal of the Royal Society for the Promotion of Health, 31, 573 - 588.

[7] Jirojwong, S., and Wang, W., (2008). Does information support and other types of support increase women's confidence in their roles as mother? International Lifelong Learning Conference. Yeppoon QLD: Central Queensland University 
[8] Billington, D. D., (1990). Adult learning can stimulate personal development Australian Journal of Adult and Community Education, 30, 54 - 63.

[9] Langton Hewer, J., (1891). Our baby: For mothers and nurses, Bristol: John Wright.

[10] Stanley, F. J., (2001). Child health since Federation. In: Australian Bureau Of Statistics (ed.). Canberra, ACT: Australian Bureau of Statistics.

[11] Skinner, B. F., (1953). Science and human behaviour. New York: Macmillan. MASLOW, A. 1970. Motivation \& personality, New York: Harper \& Row.

[12] Department Of Culture And Recreation. (2010). Arts and crafts movement in Australia Canberra, ACT: Department of Culture and Recreation. http://www.cultureandrecreation.gov.au/ articlesartsandcrafts/

[13] King K. P. and Heuer B. P., (2008). Evolution of an educational research model: Transformative learning research intersecting with learners' lives across varied contexts. International Forum of Teaching Studies, 4.

[14] Fowler C., (2002). Maternal knowledge: Beyond formal learning. Australian Journal of Adult Learning, 42, 155-168.

[15] Lindeman, E. C., (1989). The meaning of adult education, Norman: University of Oklahoma.

[16] Atherton, J. S., (2010). Learning and Teaching; Knowles' andragogy: an angle on adult learning http://www.learningandteaching.info/learning/knowlesa.ht $\mathrm{m}$

[17] Smith, J., Dunstone, M. and Elliott-Rudder, M., (2009). Health professional knowledge of breastfeeding: are the health risks of infant formula feeding accurately conveyed by the titles and abstracts of journal articles? Journal of Human Lactation, 25, 350-8.

[18] South Australia Health Children Youth And Women's Health Service. (2005). History of child and youth health Adelaide, SA: South Australia Health. http://www.cyh.com/SubContent.aspx?cp=89\&p=115.

[19] Spock, B., (1946). The commonsense book of baby and childcare, New York: Duell, Sloan \& Pearce.

[20] Bowlby, J., (1951). Maternal care and mental health: a report prepared on behalf of the World Health Organisation as a contribution to the United Nations programme for the welfare of homeless children. Geneva: World Health Organisation.

[21] Kociumbas, J., (1997). Australian Childhood - A History. St Leonards, NSW: Allen \& Unwin.p.133

[22] Mein-Smith, P., (1997). Mothers and King baby. Infant survival and welfare in an imperial world Australia 1880 - 1950, London: Macmillan. 